\title{
ШКОЛЕ НУЖЕН ФЕМТОСКАН
}

\section{SCHOOL NEEDS FEMTOSCAN}

\begin{abstract}
И.В.Яминский', 2, 3, д.ф.-м.н., проф. МГУ имени Ломоносова, физический и химический факультеты, генеральный директор Центра перспективных технологий, директор Энергоэффективных технологий (ORCID: 0000-0001-8731-3947) / yaminsky@nanoscopy.ru, А.И.Ахметова $a^{1,2,3}$, инженер НИИ ФХБ имени А.Н.Белозерского МГУ, ведущий специалист Центра перспективных технологий и энергоэффективных технологий (ORCID: 0000-0001-6363-8202)

I.V.Yaminsky', 2,3, Doctor of Physical and Mathematical Sciences, Professor of Lomonosov Moscow State University, Physical and Chemical departments, Director of Advanced Technologies Center, Director of Energy Effficient Technologies A.I.Akhmetova 1, 2,3, Engineer of A.N. Belozersky Institute of Physico-Chemical Biology, Leading Specialist of Advanced Technologies Center and of Energy Efficient Technologies
\end{abstract}

\section{DOI: 10.22184/1993-8578.2019.12.1.64.66}

Получено: 1.02.2019 г.

Попадание в топ-10 глобального рейтинга по качеству общего образования требует вовлеченности всех участников образовательного процесса и особого подхода. Технологические вызовы становятся все сложнее, и тренд на миниатюризацию не достигнет предела в ближайшие десятилетия. Электронные платы приближаются к нанометровым размерам, точность позиционирования и точность обработки станков с чПУ выходят на субмикронный уровень. В таких условиях умение пользоваться высокопрецизионным оборудованием, таким как сканирующий зондовый микроскоп, становится неотъемлемой частью школьного образования.

Getting into the top 10 global rankings on the quality of general education requires the involvement of all participants in the educational process and a special approach. Technological challenges are becoming more complex, and the trend towards miniaturization will not reach the limit in the coming decades. The electronic boards reach the nanometer size, the positioning accuracy and the precision of CNC machining reach a submicron level. In such conditions, the ability to use high-precision equipment, such as a scanning probe microscope, becomes an integral part of school education.

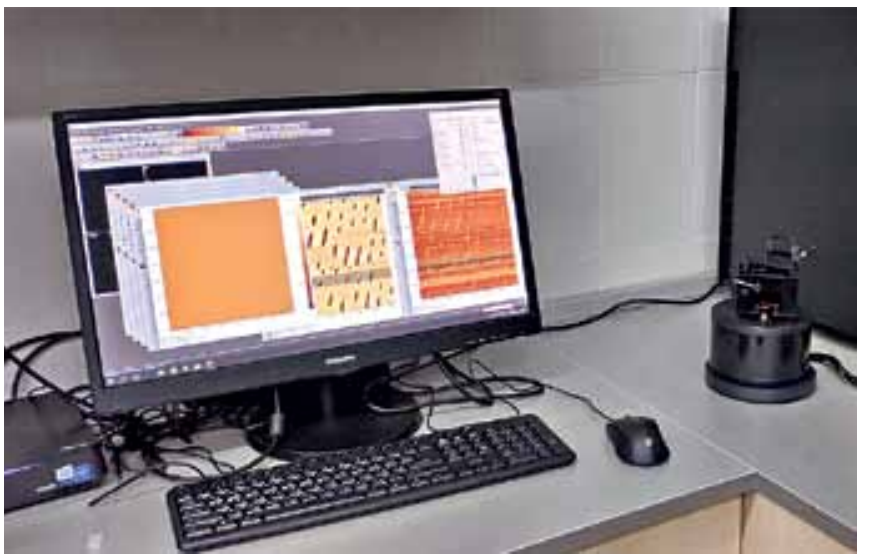

Puc.1. Сканирование поверхности пазерного диска Fig.1. Scanning of a laser disc surface

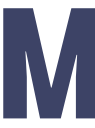

ы вступаем в эпоху, когда изучать основы нанотехнологий необходимо со школьной

скамьи. С помощью зондовой микроскопии школьникам можно просто и доступно объяснять процессы, которые происходят в нанометровом масштабе. Например, с помощью нанолитографии можно не только рисовать картинки на поверхности графита, но и узнать о таком процессе, как локальное анодное окисление. Многофункциональный сканирующий зондовый микроскоп ФемтоСкан может работать в режиме $24 \times 7$, в том числе в режиме полного удаленного доступа через Интернет. Поэтому задание по обработке полученных результатов сканирования школьники смогут делать самостоятельно дома.

\footnotetext{
МГУ имени М. В.Ломоносова, физический и химический факультеты / Lomonosov Moscow State University, Physical and Chemical departments. ООО НПП "Центр перспективных технологий" / Advanced Technologies Center.

ООО "Энергоэффективные технологии" / Energy Efficient Technologies.
} 


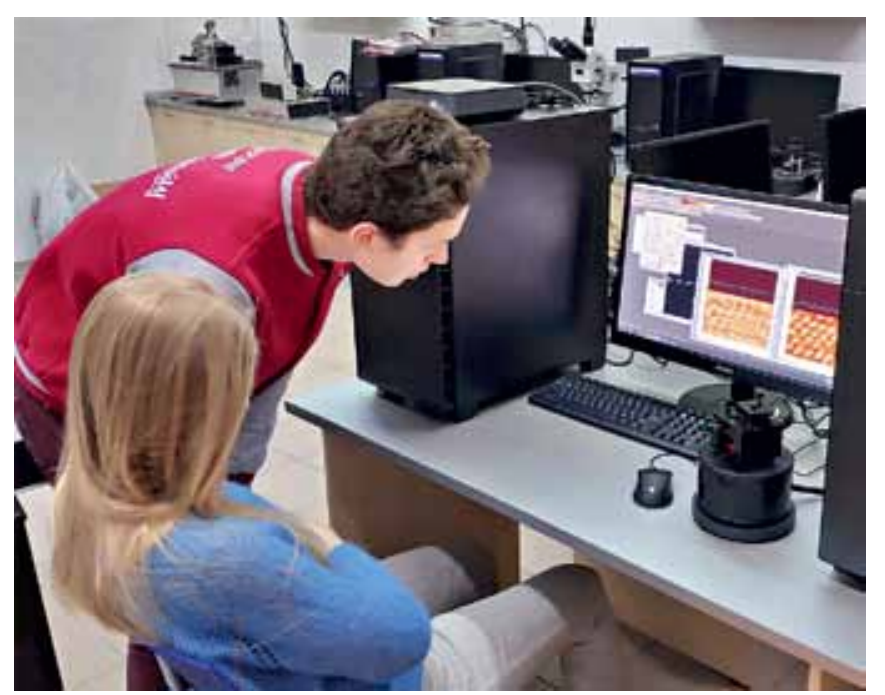

Pис.2. Класс по зондовой микроскопии в Кванториуме (2. Королев)

Fig.2. Probe microscopy practical studies at Quantorium (Korolev)

В рамках занятий по зондовой микроскопии в школе можно проводить специальные лабораторные работы, разработанные и апробированные нами со школьниками:

- "Сканирующая зондовая микроскопия: получение трехмерных изображений";

- "Обработка изображений сканирующей зондовой микроскопии";

- "Основы работы на сканирующем зондовом микроскопе";

• "Атомно-силовая микроскопия бактерий";
- "Изучаем блок-сополимеры";

- "Вирус табачной мозаики".

Серия лабораторных работ по атомно-силовой и сканирующей резистивной микроскопии графита, графена и оксидов графита и графена постоянно совершенствуется. С помощью сканирующей зондовой микроскопии можно исследовать строение, физико-химические и электрофизические характеристики 2D-структур, что особенно интересно при разработке энергонакопителей и катализаторов на основе углеродных материалов [1]. Используя сканирующую зондовую и капиллярную микроскопии, мы устанавливаем взаимосвязи между топографией поверхности и ее электрофизическими свойствами с пространственным разрешением на уровне десятка нанометров.

Если у вас в школе пока нет зондового микроскопа, вы можете начать с нашего онлайн-курса. В рамках дистанционного эксперимента на образовательной платформе "Стемфорд" вы узнаете в деталях, как проводить исследования бактерий на сканирующем зондовом микроскопе. Ближайшая экспериментальная сессия состоится 19 апреля 2019 года, желающие могут записаться на сайте stemford.org. "Стемфорд" - это образовательная онлайн-платформа, на которой школьники могут получать дополнительное образование по естественно-научным и инженерным тематикам (проект реализуется АНО "Электронное образование для наноиндустрии" при поддержке Фонда инфраструктурных и образовательных программ).

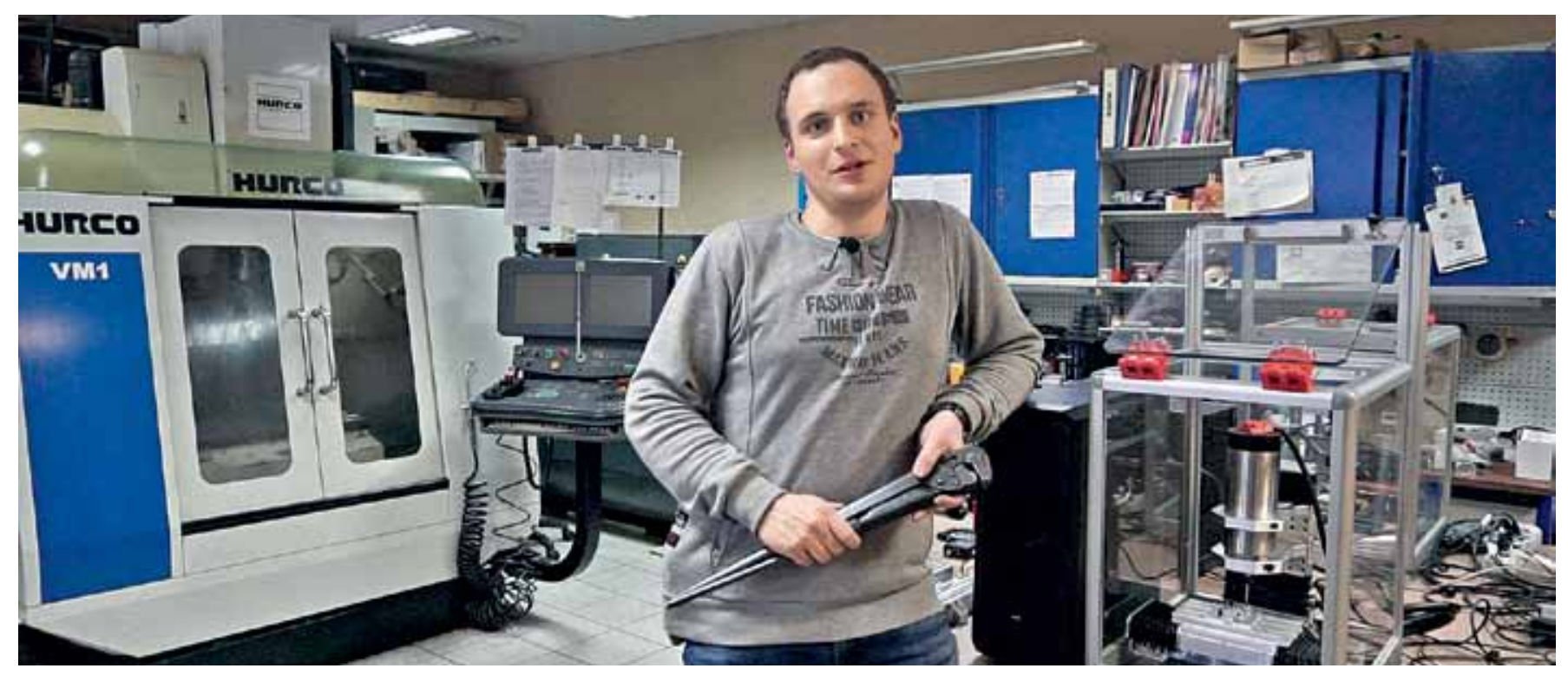

Рис.3. Сотрудник ЦМИТ "Нанотехнологии" Белов Юрий Кириллович рассказывает, как создать деталь на станке с Чпу Fig.3. An employee of the Youth Innovative Creativity Centre "Nanotechnology" Belov Yuri Kirillovich tells how to create a detail on a CNC machine 


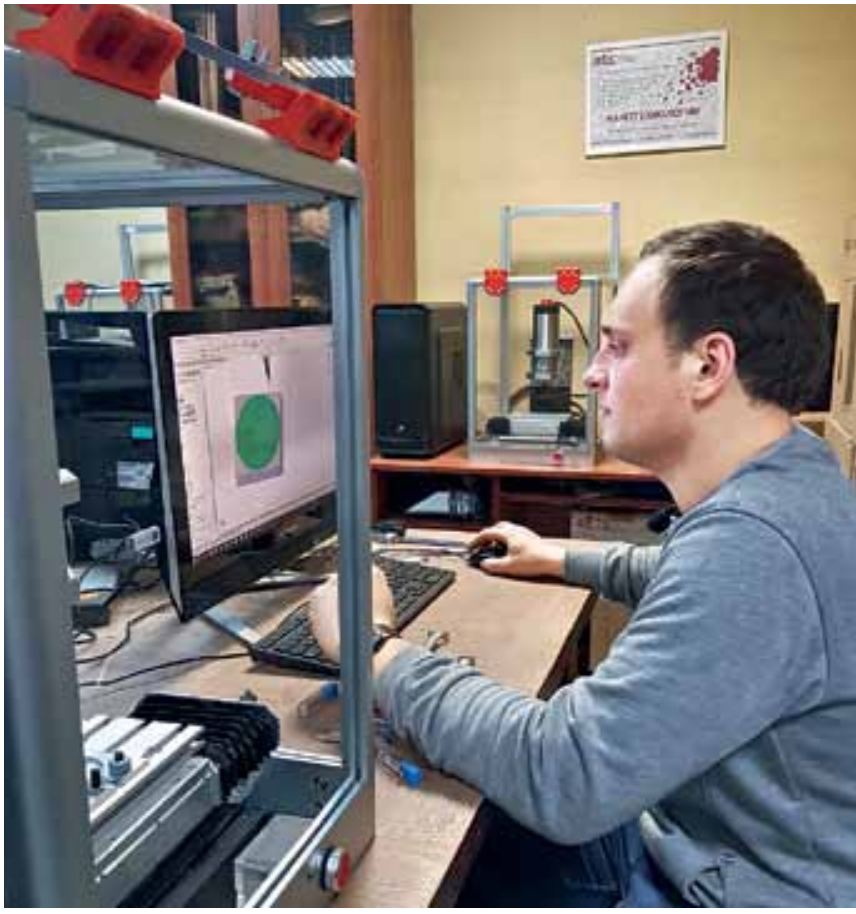

Рис.4. Ю.К.Белов создает в программе SolidWorks модель детали дия станка с ЧПУ

Fig.4. Yu.K.Belov creates a model of a detail for a CNC machine using a computer

Также на платформе "Стемфорд" в феврале состоялся вебинар "Как создать деталь на станке с чПу" на примере изготовления логотипа из оргстекла на трехкоординатном фрезерногравировальном станке с чПУ ATCNano (см. рис.2).
А тем, кому онлайн-вебинара было недостаточно, всегда могут записаться на курс "3D проектирование в SolidWorks и механообработка" в МГУ имени M.В.Ломоносова. На занятиях вам расскажут, как создавать 3D-модель будущей детали в программе SolidWorks, как формировать стратегию обработки заготовки и как управлять станком с ЧПУ [2].

В рамках проекта по совершенствованию малогабаритного станка с ЧПу сейчас ведутся работы по созданию системы автоматической замены инструмента, что позволит исключить оператора в процессе изготовления сложных элементов. Таким образом, станок становится удобным малогабаритным инструментом для моделирования и прототипирования.

Авторы выражают благодарность за финансовую поддержку Российскому фонду фундаментальных исследований (проект № 16-29-06290) и Фонду содействия инновациям (договор 422ГРНТИС/44715).

\section{ЛИТЕРАТУРА}

1. Akhmetova A.I., Meshkov G.B., Sinitsyna O.V., Yaminsky I.V. Nanoscopy methods for directed modification of nanoscale 2D structures and determination of their physicochemical and electrophysical characteristics // Nanoindustry. 2018. Vol.11, No.4 (83), pp. 246-249.

2. Yaminsky I.V., Akhmetova A.I., Belov Yu.K. Nano-lathe // Nanoindustry. 2018. Vol. 11, No.6 (85), pp. 446-448.

\section{КИТАЙСКИЕ УЧЕНЫЕ ОСУЩЕСТВИЛИ ПРОРЫВ В ПОНИМАНИИ МЕХАНИЗМОВ РАЗВИТИЯ ШИЗОФРЕНИИ}

Шанхайские ученые обнаружили, что объем путамена, подкорковой области человеческого мозга, у подростков может служить индикатором вероятности возникновения и развития шизофрении после полового созревания.

Это открытие может помочь ученым лучше понять работу генеративных механизмов заболевания, что позволит по-новому взглянуть на изучение превентивного вмешательства до появления клинических симптомов, считает исследовательская группа из Института науки и технологии, проводившая исследования по изучению работы мозга в Фуданьском университете (г. Шанхай, КНР).

Исследование было основано на компьютерном анализе более 10 тыс. образцов данных генетики изображений из более чем 20 учреждений шести стран - США, Канады, Франции, Германии, Великобритании и Северной Ирландии. Исследовательская группа сообщила, что образец открытия представлял собой продольную нейровизуализованную когорту из примерно 2 тыс. здоровых подростков.

"Это может быть первый случай, когда китайская исследовательская группа провела свое исследование на основе таких больших данных как нейровизуализации, так и генетических данных из зарубежных стран. Это повод гордиться нашими исследованиями", - заявил Фэн Цзяньфэн, руководитель исследовательской группы.

В четверг в американском научном жүрнале JAMA Psychiatry была опубликована статья о результатах этой работы, основанной на скрупулезном пятилетнем исследовании. Один из исследователей, Ло Цян, сообщил, что их группа продолжит тестирование на животных, чтобы определить патогенез этого заболевания. 